\title{
LABORATORY MODELLING OF ROCK JOINTS UNDER SHEAR AND CONSTANT NORMAL LOADING
}

\author{
G Budi ${ }^{1}$, K.U.M. Rao ${ }^{2}$, Debasis Deb ${ }^{3}$ \\ ${ }^{1}$ Assistant professor, Department of Mining Engineering, Indian School of Mines, Dhanbad, Jharkhand, India \\ ${ }^{2}$ Professor, Department of Mining Engineering, Indian Institute of Technology Kharagpur, West Bengal, India \\ ${ }^{3}$ Professor, Department of Mining Engineering, Indian Institute of Technology Kharagpur, West Bengal, India
}

\begin{abstract}
In this paper, the shear behaviour of artificial rock joints under constant normal loading conditions is studied. Idealised joint surfaces were prepared using a developed molding method with special mortar and shear tests were performed on these samples under CNL conditions. Different levels of normal load and shear displacement were applied on the samples to study the shear behaviour of sawtooth shaped joints before and during considerable relative shear displacement. Nine types of saw-tooth joints have been selected for simplicity of modelling to quantify the effect of CNL conditions on joint shear behaviour. It was found that the shear strength of joints is related to rate of shear displacement, joint roughness and applied normal stress condition. Finally, based on the experimental investigations and observations made of sheared joint samples, four conceptual models of shear stress-shear displacements have been developed. These four models summarize the entire experimental results based on elastic, dilation and residual zone defined along the shear displacement axis. The findings of this study expand current state of knowledge of joint shear strength which may be of significance for further research and for understanding the shear behaviour of rock joints for a stability analysis of the designed structures in surface and underground rock engineering.
\end{abstract}

Keywords: shear strength, artificial rock joints, direct shear test, constant normal loading

\section{INTRODUCTION}

The performance of surface and underground excavations with respect to its design objectives is controlled by the stresses and displacements that develop during and after excavation under the prevailing in situ stresses, induced stresses, ground water pressure distribution and causes stress concentration around the opening. The spatial distribution of rock mass strength and deformability and especially the intersecting discontinuities such as joints, fractures, faults, and bedding planes make the stress distribution and associated deformation highly discontinuous. Being generally weak, these discontinuities will directly influence rock mass deformation and stability of the underground structures under various loading conditions [1]; [2]. The stability of underground mine excavations, tunnels, open pit slopes and others in a jointed rock mass is influenced by the shear-strength characteristics of the joints.

Surface and underground openings are created for many purposes. The openings such as tunnels, large underground caverns for hydro-electric projects, underground storage facility for cryogenic purposes (storage of very low temperature material - LNG) and lastly the nuclear waste repositories (very high temperature material) have no time limit. The stability requirements are for indeed for an infinite time. Contrary to this, the underground excavations for mineral extraction have a defined life, until the complete extraction of the mineral resource. The design and construction of these engineering structures in rock mass encounter unique problems mainly due to the nature and the variability in the strength of the rock mass and also due to the pre-existing stresses in the ground. Movements along rock joints in surface or underground excavations such as underground openings, foundation of dams, tunnels, and slopes can occur in any direction, depending on kinematic constraints and the external forces (including water pressures, and forces induced by earthquakes) acting on the structure. Therefore, it is imperative to understand the variation of shear strength of rock joints for the stability analysis of these rock structures. The preliminary condition to be considered explicitly in assessing the performance of underground excavations is to study the rock joints response under static normal loading conditions. Majority of works are based on the laboratory investigations using the conventional direct shear apparatus, where the shear load is varied while keeping the normal load constant (CNL method, where in the normal stress acting on the joint interface is considered to be constant throughout the shearing process). The extensive literature has revealed that there are many aspects which influence the shear characteristics of rock joints. One of the fundamental issues is the rock joint surface roughness.

Much of the earlier works of underground opening stability studies were focused on the static stability where the initial 
peak shear strength is the principal concern. The need has arisen to assess the rock mass failures due to rock burst, explosions and other seismic activity. It is therefore essential to trace a complete shear stress-displacement relationship for rock joints from pre-peak to their residual state. Essentially, the shear stress-displacement curves of rock joints generally fall into two classifications. Some shears reach peak strength, drop off rapidly and finally taper off in strength to a residual value. Others behave more or less plastically with little or no distinct peak. Actually this type of shear stress-displacement curve is greatly influenced by the joint surface roughness. These changes can be related to the selective destruction of the asperities present on both joint faces. Since this information is usually not complied, the transition from peak to residual values if often assumed to decrease either linearly to exponentially when the joints exhibit strain softening behaviour [3]. Therefore any attempt to understand the progressive failure process after the first peak strength is a meaningful matter.

In this paper, the results of an experimental investigation carried out under CNL conditions on artificial saw-tooth joints by using a conventional direct shear test machine will be presented. Nine types of saw-tooth joints have been selected for simplicity of modelling to quantify the effect of CNL conditions on joint shear behaviour. Although idealised triangular asperities do not perfectly represent the more irregular or wavy joint profiles in the field, they still provide a simplified basis to understand the effect of varying normal load and shear rate on joint deformation. Based on the experimental results, four conceptual models of shear stressshear displacements have been developed.

\section{SHEAR STRENGTH MODELS FOR ROCK JOINTS}

Several criteria have been proposed in past to identify the strength of a joint. They delineate the state of stress that separates pre-sliding and post-sliding of the joint. The simplest constitutive model for rock joints is perhaps the Coulomb friction law in which the joint behavior is simply characterized by a single value of friction angle.

Patton [4] was the first researcher in rock mechanics to relate the shear behaviour of joints to normal load and roughness. Patton proposed a bilinear envelope that describes fairly well the shear strength of plane surfaces containing a number of regularly spaced teeth of equal dimensions. However, these criteria are not satisfactory for describing the shear behaviour of irregular rock surfaces, for which continuous failure envelopes are normally obtained. Again looking at twodimensional saw-tooth profiles, the transition from dilatancy to shearing was studied theoretically and experimentally by Ladanyi and Archambault [5] who approached the problem of joint-shear strength by identifying the areas on the joint surface where sliding and breaking of asperities are most likely to occur. Ladanyi and Archambault's shear-strength model was later reviewed by Saeb [6] in light of the stressdilatancy theory of sand.

Some more complicated joint models appeared later accompanying the development of numerical methods. Notable among them are Barton empirical model [7], AmadeiSaeb's analytical model [8] and Plesha's theoretical model [8]. All of them are two-dimensional models. However, among all the models, Barton's criterion is the only that is currently used in practice. Its approach is based on the choice of the correct value for the roughness parameter, the joint roughness coefficient (JRC). Based on tests carried out on natural rough joints, Barton derived the following empirical equation:

$$
\tau=\sigma_{n} \tan \left(J R C \log _{10}\left(\frac{J C S}{\sigma_{n}}\right)+\phi_{b}\right)
$$

where the $J R C$ (Joint Roughness Coefficient) represents a sliding scale of roughness which varies from approx. 20 to 0 , from the roughest to the smoothest end of the spectrum which was adopted by the International Society for Rock Mechanics as standard profiles for estimating joint roughness and JCS is given by unconfined compression strength $\left(\sigma_{c}\right)$ of the rock (if the joint is unweathered), but may reduce to $0.25 \sigma_{c}$ if the walls are weathered [7].

\section{LABORATORY TESTING PROGRAMME}

The aim of laboratory investigation is to establish the likely shearing mechanisms involved when testing artificial rock joints. It is basically impossible to use natural joints for systematic laboratory testing because of the problem of obtaining the same surface geometry for repeated tests. It is always better to match the surface profile of the natural joints using laboratory models. Therefore, to study the frictional response of rock joints, more than $288 \mathrm{CNL}$ direct-shear tests were performed on saw-tooth joints. Direct shear apparatus is suitably designed and fabricated for conducting CNL tests for a maximum normal load of $5000 \mathrm{kN} / \mathrm{m}^{2}$ and a maximum shear load of $50 \mathrm{kN}$ was used in the laboratory programme. It is a constant rate of strain type of equipment and gives 72 rates of deformation, suitable for operation on 415 volts, 50 cycles, three phase AC supply. In this study, the CNL shear tests have been designed in cement-sand cast models with nine variations of inclination angle $(i)$ of saw-tooth joints $\left(i=5^{\circ}, 10^{\circ}, 15^{\circ}, 20^{\circ}\right.$, $25^{\circ}, 30^{\circ}, 35^{\circ}, 40^{\circ}$, and $45^{\circ}$ ) with four variations of normal stress $(0.25,0.5,1.0$ and $1.5 \mathrm{MPa})$ and four variations of shear displacement rate $(0.314,0.502,0.719$ and $1.01 \mathrm{~mm} / \mathrm{min})$. Based on the experimental results, observations are made to identify mechanisms that have important effects on the deformation behaviour of an artificial rock joint.

In order to have a rock joint with well-defined triangular asperities, the rock joints are simulated in laboratory. The 
material used for sample preparation was cement, sand and water taken in the 1:2:0.6 by weight. In the testing programme, cement cast models (Fig.1a) were used to represent the idealized rock joints. The specimen is made in two halves of size $10 \mathrm{~cm} \times 10 \mathrm{~cm} \times 5 \mathrm{~cm}$ each. The basic properties of the model material were determined by conducting uniaxial compression tests on cylindrical specimens with $54 \mathrm{~mm}$ in diameter and $110 \mathrm{~mm}$ in height after a curing period of 28 days. The unconfined compressive strength of the simulated material was $26.85 \mathrm{MPa}$, its tensile strength (determined by Brazilian tests) was about $2 \mathrm{MPa}$ after $24 \mathrm{~h}$. The average Young's modulus is $2548 \mathrm{MPa}$, and the average Poisson's ratio is 0.2. Because of the need for repetitive tests, model rock joints with a regular saw-toothed surface profiles (asperity angle, $i=5^{0}$ to $45^{\circ}$ ) are fabricated (Fig.1a). Nine types of roughness profiles of joint surfaces having various asperity angles and their corresponding asperity heights are shown in Figure 2a.

This direct shear apparatus consists of a shear box which is made in two halves. The top box is $100 \mathrm{~mm}$ long, $100 \mathrm{~mm}$ wide and $50 \mathrm{~mm}$ high, and the bottom box is $100 \times 100 \times 50$ $\mathrm{mm}$. For measuring the shear load a high sensitivity proving ring of $50 \mathrm{kN}$ capacity was used. Shear and normal displacements were measured by two dial gauges in each direction. Fig. 1b shows the testing apparatus.

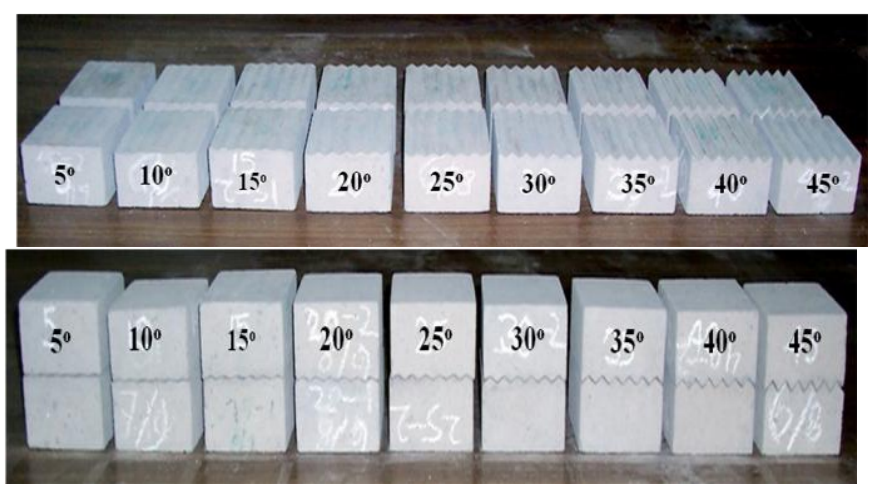

Fig -1 a: Photographs of prepared saw-tooth joint specimens

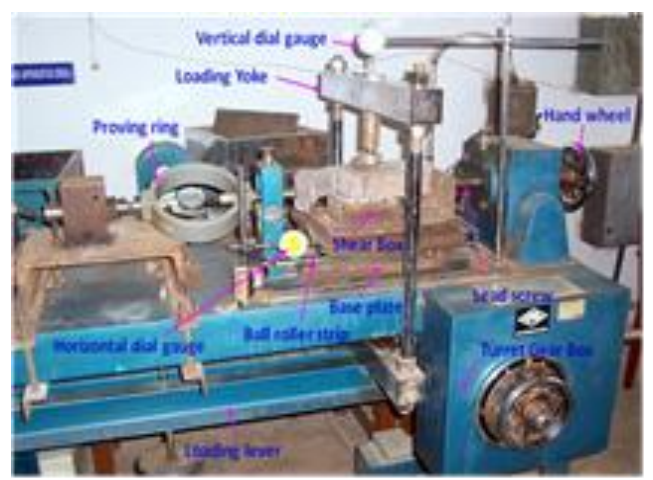

Fig -1b: Shear apparatus suitably designed and fabricated for conducting CNL tests.

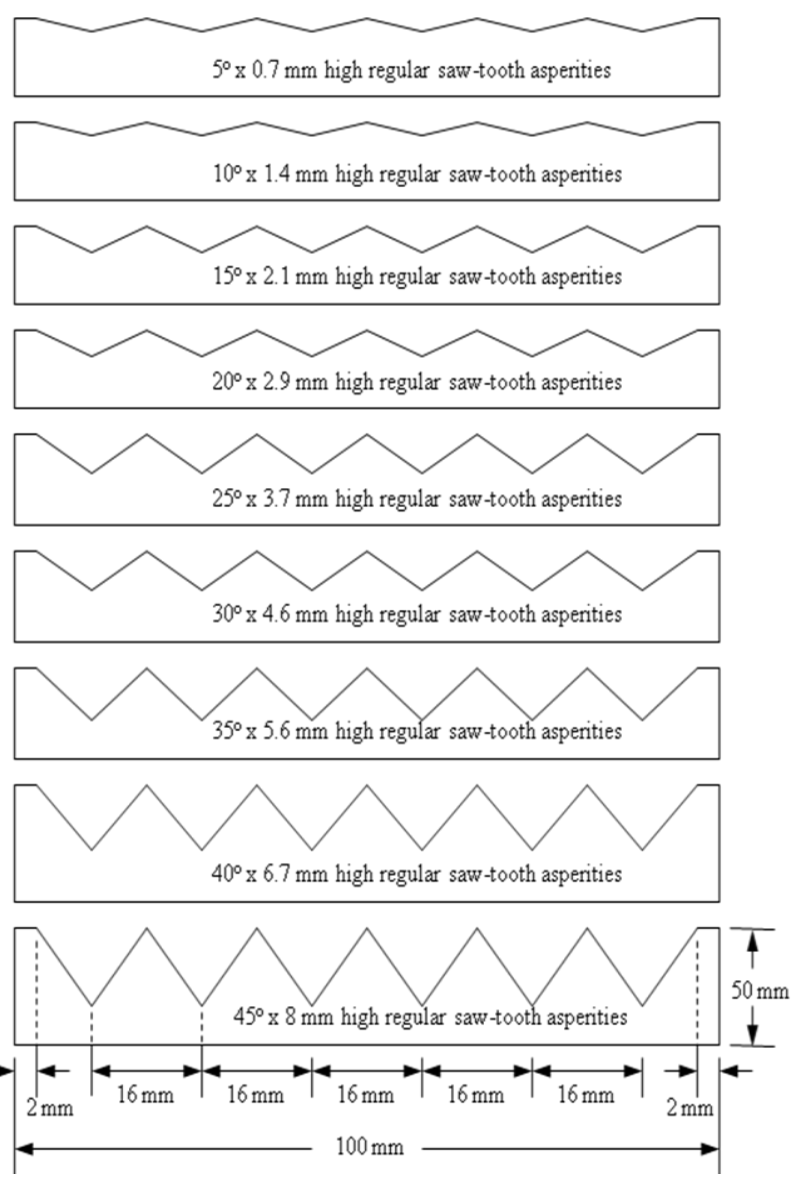

Fig -2a: Schematic diagram of various roughness profiles used in direct shear testing (not scaled).

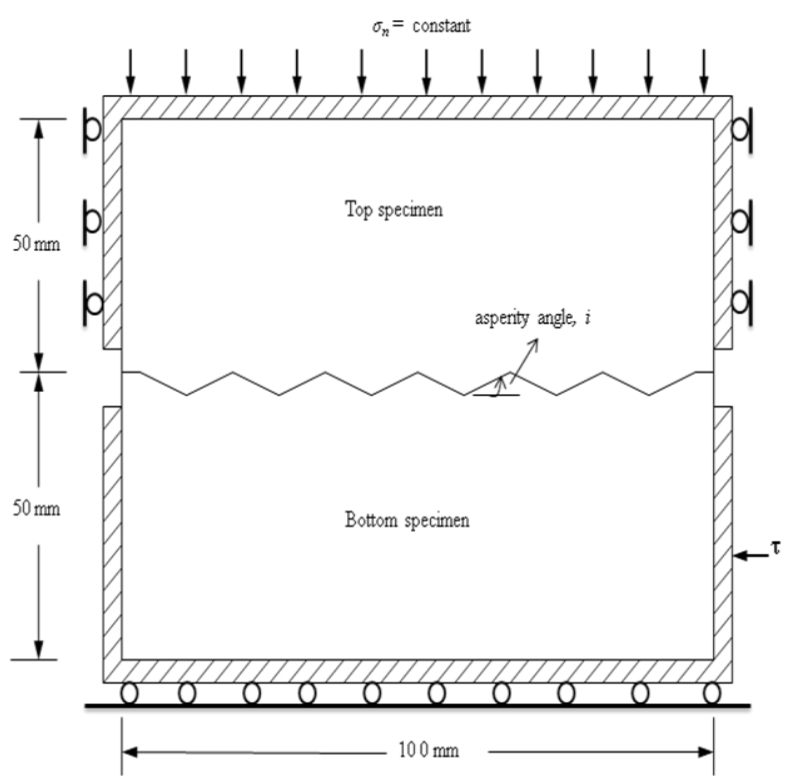

Fig -2b: Schematic diagram of the CNL shear test for an artificial joint specimen with regular saw-tooth asperities. 


\section{EXPERIMENTAL RESULTS}

The direct shear tests were performed to study the behaviour of the saw-tooth joint samples during small shear displacements. Variations in shear strength in CNL loading conditions under different shearing rates, varied joint surfaces (joint asperity angles) and normal stresses were studied. More than 200 interlocked (mating) jointed block samples were tested in the laboratory under constant normal loading conditions. The results of some of the tests performed will be presented and discussed in this paper.

The shear responses and actual shear failure modes of each joint were observed during different stages of laboratory experiments. During shearing, shear load together with the dilation and horizontal displacements are recorded. In this paper Type 1 to Type 9 joints are defined depending on asperity angle $i=5^{\circ}$ to $45^{\circ}$. The normal stresses $\sigma_{n}<1.0$ $\mathrm{MPa}$ (e.g., 0.25 and $0.5 \mathrm{MPa}$ ) and $\sigma_{n} \geq 1.0 \mathrm{MPa}$ (e.g., 1.0 and 1.5 $\mathrm{MPa}$ ) are defined as low normal stresses and high normal stresses respectively. The asperity angles $i=5^{\circ}$ to $20^{\circ}$ and $i=25^{\circ}$ to $45^{\circ}$ are defined as low asperity angles and high asperity angles respectively.

\subsection{Shear Behaviour of Saw-Tooth Model Joints}

In the experimental investigations, two typical shear behaviours of joint models with saw tooth-shaped asperities were observed during different phases of experiments. The shear behavior of a rock joint depends mainly on the asperity angle and the stress ratio of $\sigma_{n} / \sigma_{c}$. The normal stress distribution carried by each asperity is mainly dependent upon the asperity angle and the asperity deformation property.

(1) Slide-up behaviour: At lower normal stress $\left(\sigma_{n}<1.0\right.$ MPa), a slide-up behaviour was noticed to be taking place and the corresponding displacement in the shear stress versus shear displacement curves indicated a more ductile behaviour (Figure 5a). It is inferred that the shear stress initially causes elastic deformation of the asperity material. The upper block slides over the lower block along the up-slope face (Figure 3a). During this movement the shear resistance is nearly constant. Gradually the shear resistance decreases after the top asperity passes the crest of the lower asperity. Under the lower stress level, sliding was accompanied by abrasion and wearing due to shear friction between two joint surfaces. A visual observation of the joint surfaces after shearing of the specimens reveals slight damage on the asperities (Figure $3 b$ ).

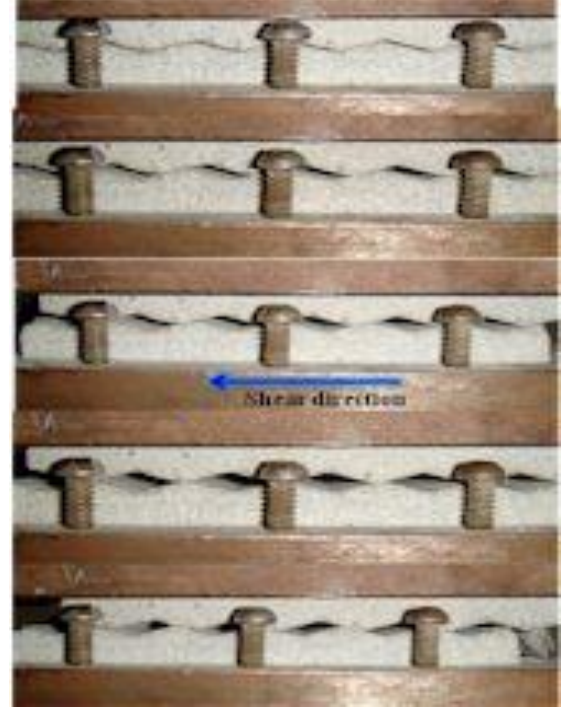

Fig -3a: Photographs Illustrating the Asperity Slide-up Behaviour during Different Stages of Shearing Process.

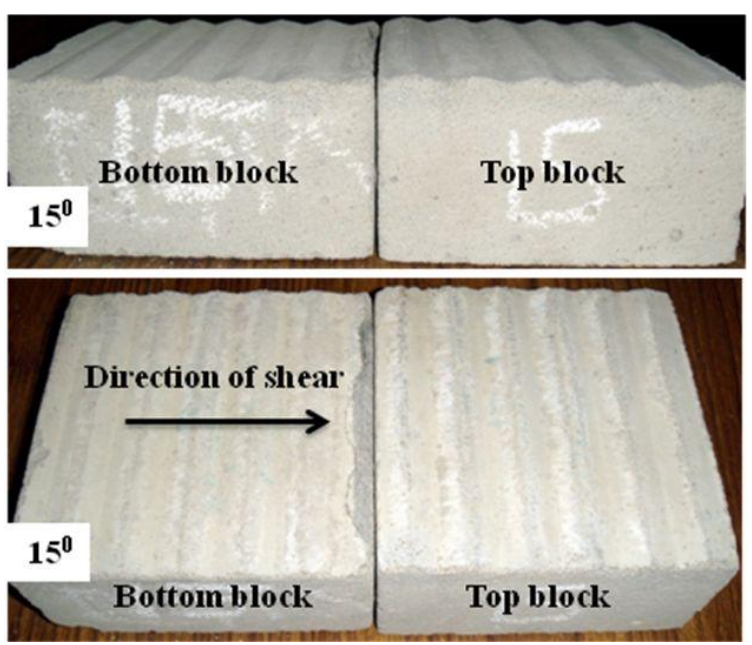

Fig -3b: Photographs Showing the Asperity Damage on Sheared Specimens. $\left(i=15^{\circ}, \sigma_{n}=0.5 \mathrm{MPa}\right.$, Shear Rate $=$ $0.502 \mathrm{~mm} / \mathrm{min}$ ) 


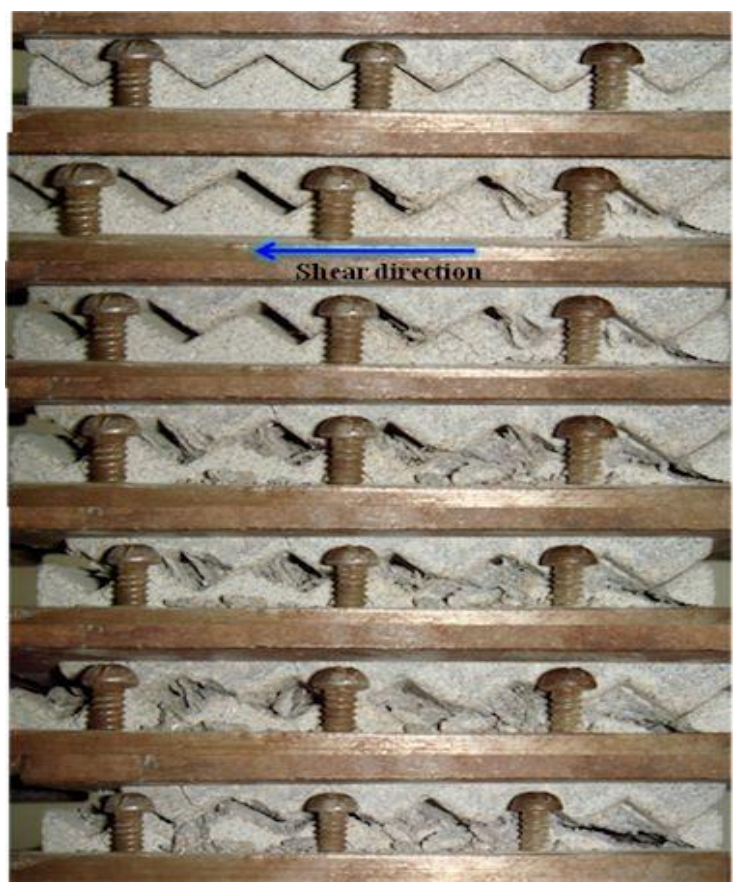

Fig -4a: Photographs Illustrating the Asperity Shear-off Behaviour during Different Stages of Shearing Process.

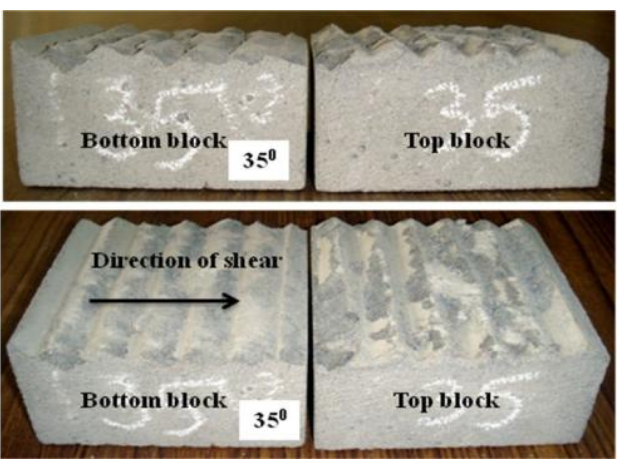

Fig -4b: Photographs Illustrating the Asperity Damage on Sheared Specimens. $\left(i=35^{\circ}, \sigma_{n}=1.0 \mathrm{MPa}\right.$, Shear Rate $=$

\section{$0.502 \mathrm{~mm} / \mathrm{min}$ )}

(2) Shear off behaviour: At higher normal stress $\left(\sigma_{n} \geq 1.0\right.$ $\mathrm{MPa}$ ), a brittle shear behaviour is observed in the shear stress versus shear displacement relationships with a sudden stressdrop after peak stress, accompanied by the asperity fracture (Figure $5 b$ ). Smaller dilation rates are recorded revealing severe damage or shear-off on the asperity. It has also been noticed from the failed samples (Figure 4b) that in a single joint sample all asperities do not get deformed completely. Rather, the frontal asperities (with respect to the direction of shearing) undergo more shear deformation compared to the rear asperities. This implies that the failure process in a rough joint is a progressive phenomenon. It is also observed that the asperity breaks in shear as well as tensile modes. Due to tight interlocking of asperities, tensile cracks are developed at the base of asperities during shear deformation. During experiments small tensile fractures in the direction nearly perpendicular to the surface are also observed at the base corner of the asperities (Fig. 4).

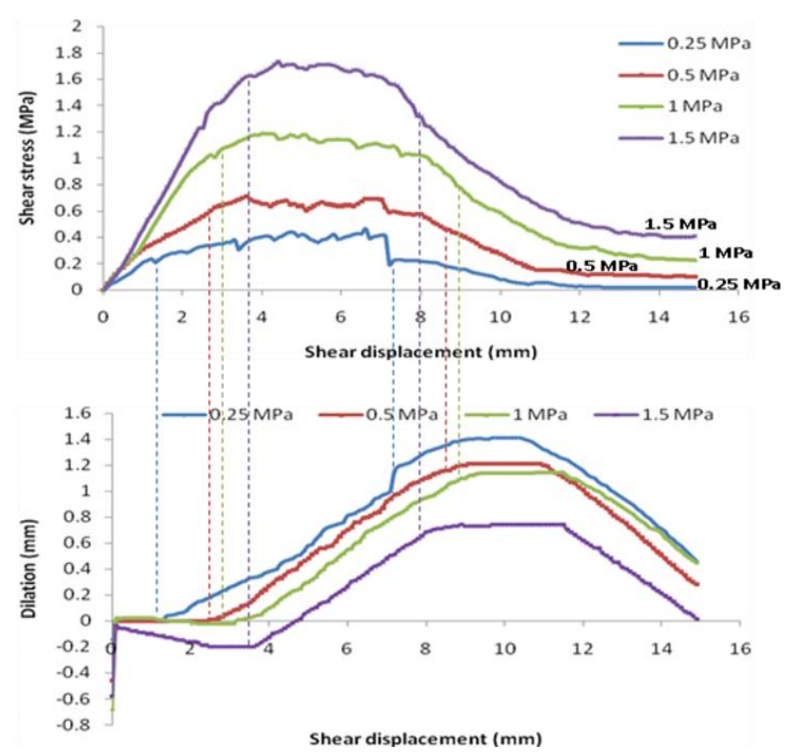

Fig -5a: Shear stress-shear displacement and dilation curves at $0.502 \mathrm{~mm} / \mathrm{min}$ shear rate, Slide-up mode (asperity angle $i=$ $\left.15^{\circ}\right)$

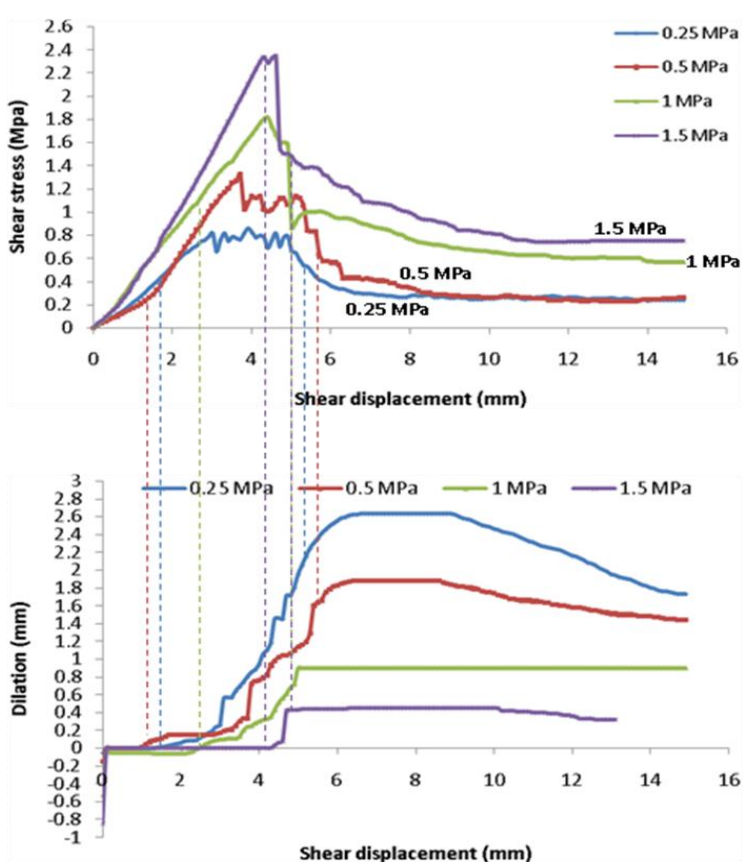

Fig -5b: Shear stress-shear displacement and dilation curves at $0.502 \mathrm{~mm} / \mathrm{min}$ shear rate, Shear-off mode (asperity angle $i=$ $40^{\circ}$ ) 


\subsection{Progressive Shear Behaviour between Low-}

\section{Angled and High-Angled Asperities}

The difference in shear behaviour between low-angled $(i$ $=5^{\circ}$ to $20^{\circ}$ ) and high-angled $\left(i=25^{\circ}\right.$ to $\left.45^{\circ}\right)$ asperities under normal stresses of $0.25,0.5,1$ and $1.5 \mathrm{MPa}$, are discussed in this section. The findings are based on the shear stress-shear displacement and, dilation-shear displacement relationships at a specific shear rate of $0.502 \mathrm{~mm} / \mathrm{min}$. The Figures 6 and 7 presents the description of progressive shear behaviour for low-angled and high-angled asperities in terms of three distinct zones viz. elastic, dilation and residual zones of shearing displacement.

\subsubsection{At Low Normal Stress Levels $(0.25$ and 0.5}

\section{MPa)}

Fig. 6 shows that the saw-tooth joint behave elastically upto the yield shear stress. The corresponding shear displacement from the origin is termed as "elastic zone" along the shear displacement axis. Dilation zone is the range of shear displacement within which active dilation has occurred. Residual zone along the shear displacement axis followed the dilation zone.

In the elastic zone, rate of dilation is minimal. Once the sample departs from elastic behaviour, asperities (tooth) starts to break upon additional shear displacement and thus rate of dilation is increased significantly as well as shear resistance. Since the normal stress is low one block rides over the other block. The "stick-slip" or tooth type curve in the dilation zone is the evidence of shear resistance due to newly breakage asperities and subsequently, riding over them. For high angled and low normal stress conditions, characteristics of shear stress-shear displacement curves remains the same. Similar trends in shear stress and shear displacements are observed when $\sigma_{n}$ is increased to $0.5 \mathrm{MPa}$.

Shear stress increases with shear displacement and reaches a peak value showing a stick-slip response for all the joints $(i$ $=5^{\circ}$ to $45^{\circ}$ ). This stick-slip behaviour is possibly due to the momentary reduction in shear stress as individual asperities are sheared. In case of low-angled asperities, the shear stressdisplacement curves did not show the elastic deformation region prominently and the nature of curves indicates a complete ductile and slide-up behaviour and a similar trend extended for the normal stresses up to $0.5 \mathrm{MPa}$. In case of high-angled asperities, the shear stress versus shear displacement curves indicated a brittle and shear-off behaviour with a sudden stress-drop after peak stress, accompanied by the asperity fracture (Fig. 6b).

It is also found that the peak shear strength increases with an increasing asperity angle from $i=5^{\circ}$ to $30^{\circ}$, thereafter the peak shear stress drops with increasing asperity angle. This phenomenon is recorded for all cases i.e. low/high normal stress conditions. It is possibly due to the fact that for high angled tooth, larger normal component of shear stress act on the tooth surface causing tensile cracks at the base and increasing the possibility of tooth shearing. As a result tooth resistance to shear decreasing causes low peak shear strength. This implies that for a given specimen the maximum shear strength achieves for a specified $\sigma_{n}$ when the asperity angle is close to $30^{\circ}$.

It has also been noticed from the failed samples that in a single sample all asperities do not get deformed completely. The frontal asperities, with respect to the direction of shearing, undergo more shear deformation compared to the rear asperities, which indicates that the failure in a rough joint is a progressive phenomenon. Observation of the test results suggests that the shear behaviour of saw-tooth joint surfaces is more controlled by the basic friction, friction due to the geometry of the surfaces, peak shear stress at the beginning of shearing followed by a stick-slip phenomenon.

In case of low-angled joints, it is observed that the dilation increases with increasing asperity angle, possibly due to increased asperity height and wall strength (hardness) of each surface. It is found that as the asperity height increases in joints the extent of dilation increases and also the shear resistance for the same normal stress levels. Further, it is also noticed that the rate of dilation increases as the peak shear strength is being approached. Thereafter, the rate decreased gradually with further shear displacement. As the normal stress increased to $0.5 \mathrm{MPa}$, the shearing of the asperities is indicated by a compression zone in the dilation curves. The amount of shear displacement required to reach the point of zero dilation (transition point from contraction to dilation) from the initial position increases significantly with increasing normal load.

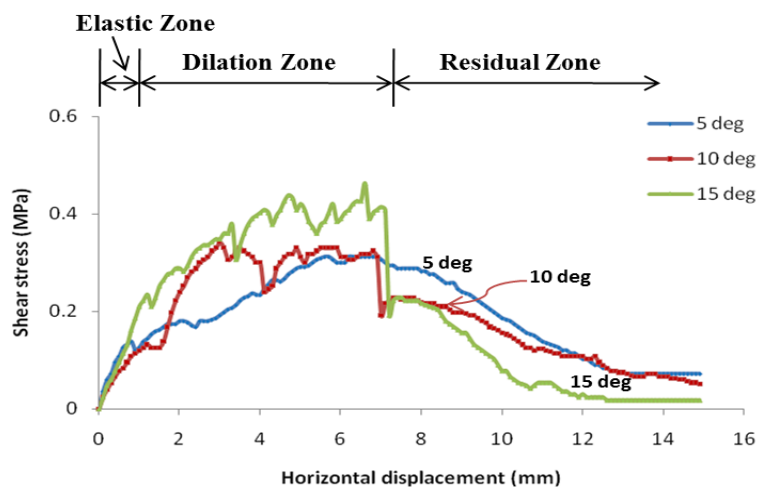

Fig -6a: Shear Stress-Shear Displacement Curves for LowAngled Asperities at $0.502 \mathrm{~mm} / \mathrm{min}$ Shear Rate $\left(\sigma_{n}=0.25\right.$ $\mathrm{MPa})$ 


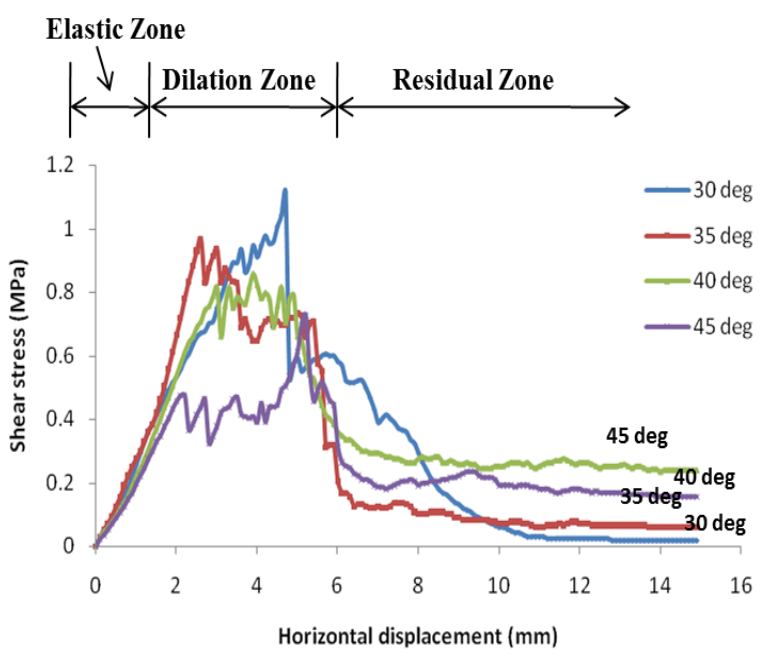

Fig -6b: Shear Stress-Shear Displacement Curves for HighAngled Asperities at $0.502 \mathrm{~mm} / \mathrm{min}$ Shear Rate $\left(\sigma_{n}=0.25\right.$ $\mathrm{MPa})$

\subsubsection{At Higher Normal Stress Levels (1.0 and 1.5} MPa)

Direct shearing of saw-tooth type joints at a normal stress level of $1 \mathrm{MPa}$ shows that as shearing proceeds, the samples undergo elastic deformation with a negligible negative dilation for a low asperity angled samples. However, for the similar conditions, significant negative dilation is observed for high asperity angled joints. On the contrary, for the specimens tested at $\sigma_{n}=1.5 \mathrm{MPa}$, the asperities are fractured after a small shear displacement, accompanied by a steep drop in shear stress (Fig.7). The initial elastic deformation in the stress-deformation curve is prominently exhibited for the normal stress level of 1.5 $\mathrm{MPa}$ and remains indicative even for $\sigma_{n}$ of 1.0 MPa. The joint stick-slip behaviour is pronounced for the normal stress level of $1 \mathrm{MPa}$. It is interesting to note that, in case of low-angled asperities, the stick-slip behaviour continues even in dilation zone which suggests that the asperities, broken off from the joint surfaces in the shearing process, also provide shear resistance to shearing process. The peak shear strength values under constant normal stress of 1.5 $\mathrm{MPa}$ is the highest for angles lying between $25^{\circ}$ to $35^{\circ}$. The recorded peak shear strength values are 2.478, 2.646 and 2.49 $\mathrm{MPa}$ for asperity angles of $25^{\circ}, 30^{\circ}$ and $35^{\circ}$ respectively at $0.502 \mathrm{~mm} / \mathrm{min}$ shear rate.

The amount of shear displacement from the initial position required to reach the point of zero dilation (transition point from contraction to dilation) increases with increasing normal stress. At $\sigma_{n}=1 \mathrm{MPa}$, for low angled and high normal stress conditions elastic zone is measured about 2 to $3 \mathrm{~mm}$. The "stick-slip" or tooth type curve in the dilation zone is the evidence of shear resistance due to asperity degradation and subsequently, riding over them. For high angled and high normal stress conditions, characteristics of shear stress-shear displacement curves tend to be brittle in nature as compared to the ductile behaviour of the low angled joints. Similar trends in shear stress and shear displacements are observed when $\sigma_{n}$ is increased to 1.5 MPa. At higher normal stress, high elastic zone is noticed in high-angled joints (Fig. 7).

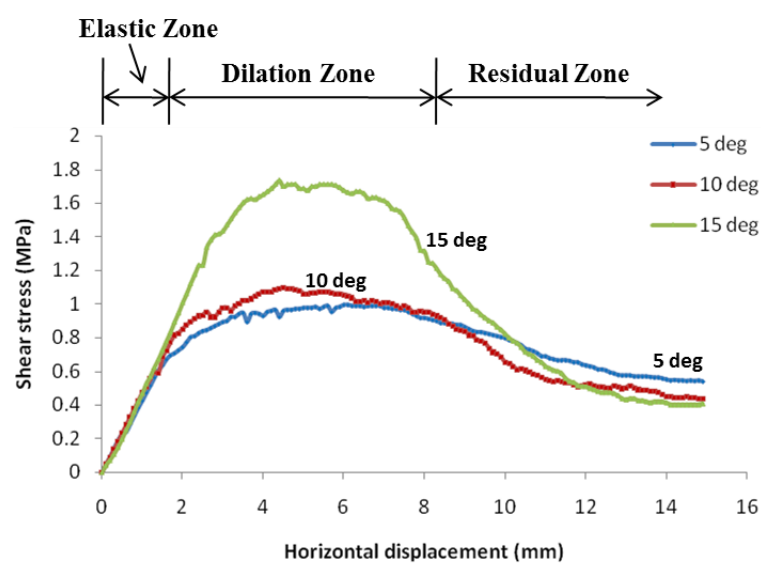

Fig -7a: Shear Stress-Shear Displacement Curves for LowAngled Asperities at $0.502 \mathrm{~mm} / \mathrm{min}$ Shear Rate $\left(\sigma_{n}=1.5\right.$ $\mathrm{MPa})$

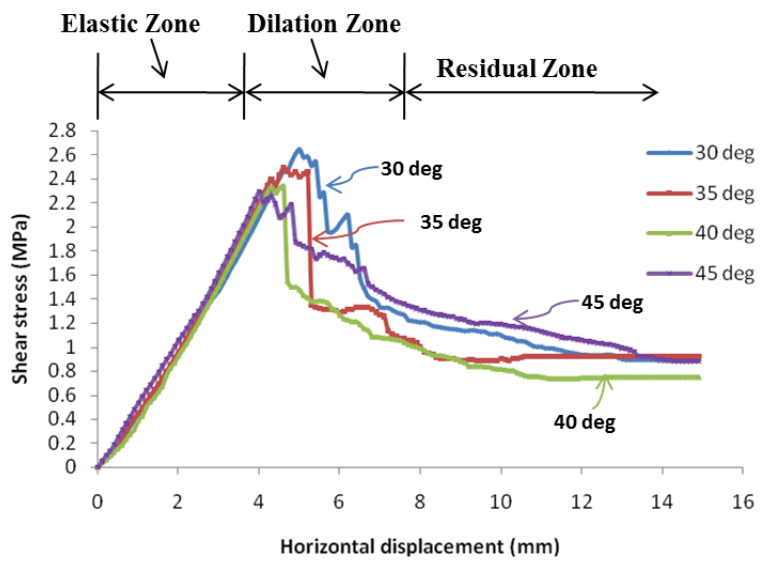

Fig -7b: Shear Stress-Shear Displacement Curves for HighAngled Asperities at $0.502 \mathrm{~mm} / \mathrm{min}$ Shear Rate ( $\sigma_{n}=1.5$

$\mathrm{MPa})$ 


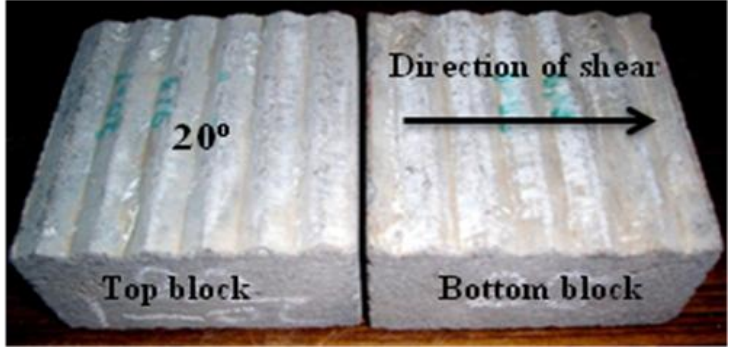

Fig -8a: Photographs of tested specimens illustrating the asperities wear after shearing for an asperity angle, $i=20^{\circ}$ $\left(\sigma_{n}=0.25 \mathrm{MPa}\right)$

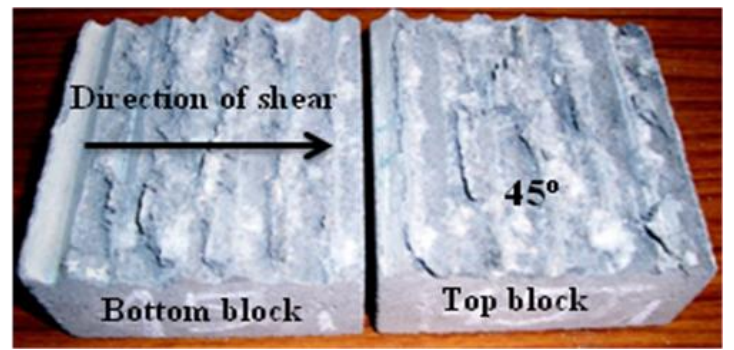

Fig -8b: Photographs of tested specimens illustrating the asperities wear after shearing for an asperity angle, $i=45^{\circ}\left(\sigma_{n}\right.$ $=1.5 \mathrm{MPa})$

\subsection{Effect of Shear Displacement Rate on Shear Stress Response}

The influence of shear displacement rate on shear stress and the corresponding displacements, as shown in Fig. 9 (a) and (b), shows an insignificant influence for different joints $\left(i=5^{\circ}\right.$ and $35^{\circ}$ ). It is observed that peak shear stress slightly increases with an increasing in shear displacement rate from 0.314 to $1.01 \mathrm{~mm} / \mathrm{min}$ under given normal stress conditions. The observed values of the peak shear strength at $1.01 \mathrm{~mm} / \mathrm{min}$ shear rate is the highest for tooth angles lying between $25^{\circ}$ to $35^{\circ}$. The recorded peak shear strength values are 2.934, 3.306 and 2.598 MPa for asperity angles of $25^{\circ}, 30^{\circ}$ and $35^{\circ}$ respectively at a constant normal stress of $1.5 \mathrm{MPa}$. It is found that the rate of shear displacement has a little or insignificant effect on the peak shear stress for the saw-tooth jointed samples. The variation of shear strength with different shear rates for different asperity angles $\left(i=5^{\circ}\right.$ to $\left.45^{\circ}\right)$ is shown in Fig. 10.

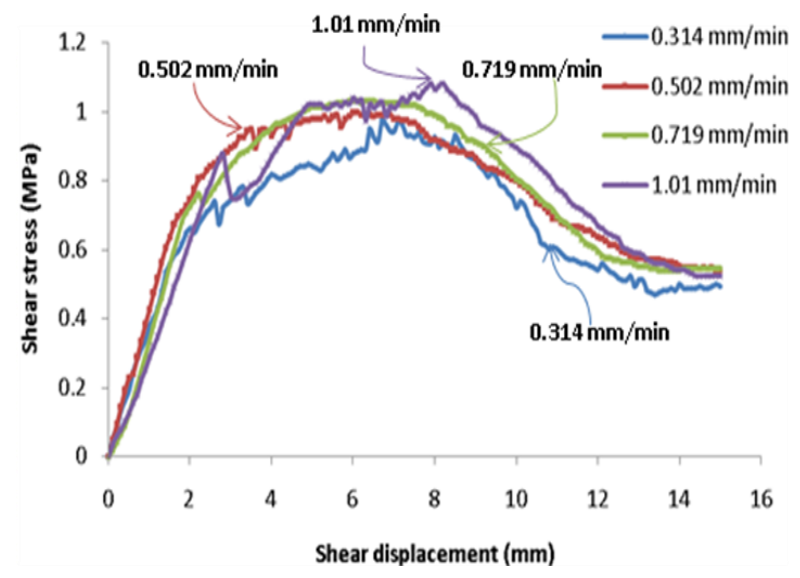

Fig -9a: Shear stress-shear displacement curves $\left(\sigma_{n}=1.5\right.$ $\mathrm{MPa}$ ) for an asperity angle, $i=5^{\circ}$

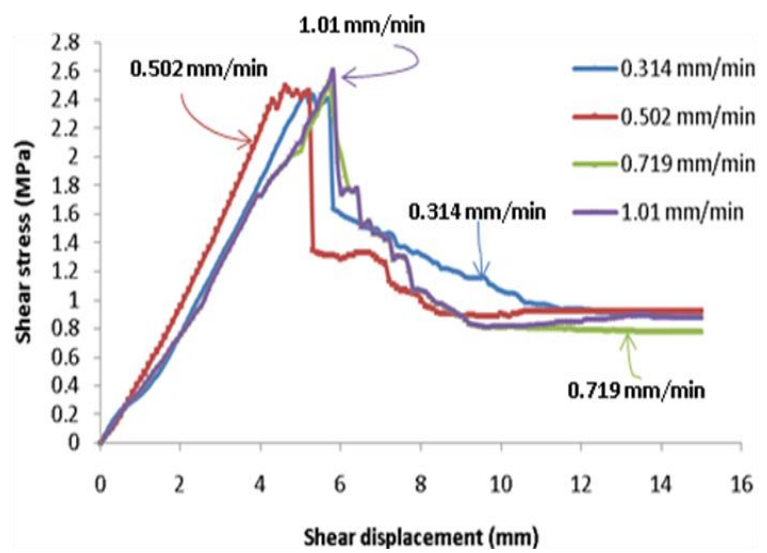

Fig -9b: Shear stress-shear displacement curves $\left(\sigma_{n}=1.5\right.$ $\mathrm{MPa}$ ) for an asperity angle, $i=35^{\circ}$

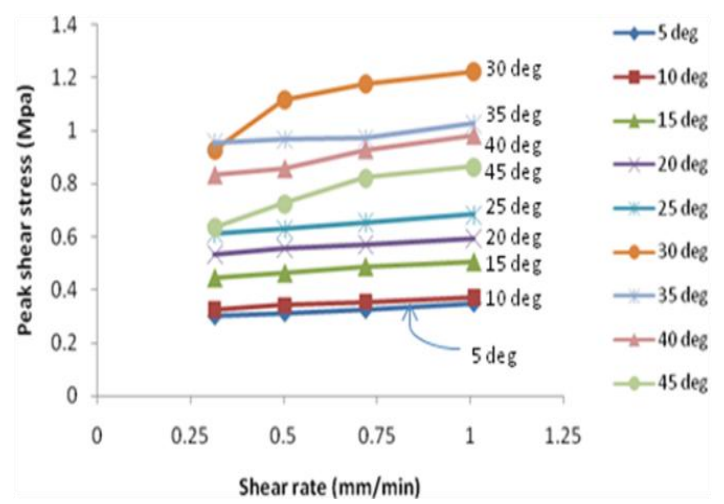

Fig -10a: Effect of shear rate on the peak shear stress at $\sigma_{n}=$ $0.25 \mathrm{MPa}$ 


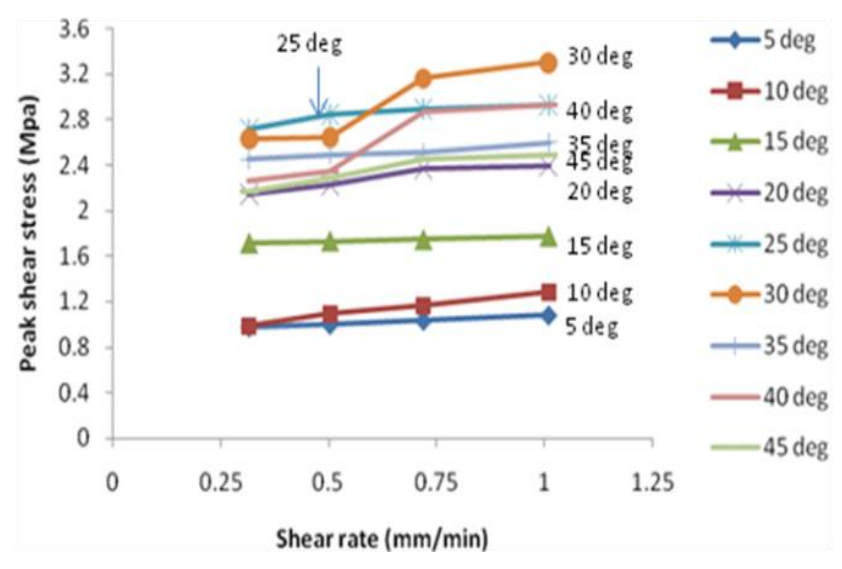

Fig -10b: Effect of shear rate on the peak shear stress at $\sigma_{n}=$ $1.5 \mathrm{MPa}$

\subsection{Conceptual Models of Shear Stress-Shear Displacement Curves for Saw-Tooth Joints}

Based on entire experimental investigations, four conceptual models are proposed between shear stress and shear displacement relationships for saw-tooth shaped joint asperities (Fig.11). These four models are developed based on the following conditions: (a) Low angled - Low normal stress condition (b) Low angled - High normal stress condition (c) High angled - Low normal stress condition and (d) High angled - High normal stress condition. The shear stress-shear displacement curves are sub-divided into three distinct zones (elastic, dilation and residual zones) depend upon the normal stress level and asperity angle.

These zones are unique of each of the model described above. Low elastic zone is expected for model 1 (Low angled - Low normal stress) but dilation zone will be larger with lower peak shear strength. The peak shear strength can be about 2 times higher than the model 1 . High peak shear strength is expected for model 4 as compared to model 1, model 2 and model 3. In nutshell, dilation zone increases for lower normal stress and lower asperity angles of the joints. On the contrary, elastic zone increases with higher normal stresses and higher asperity angles.

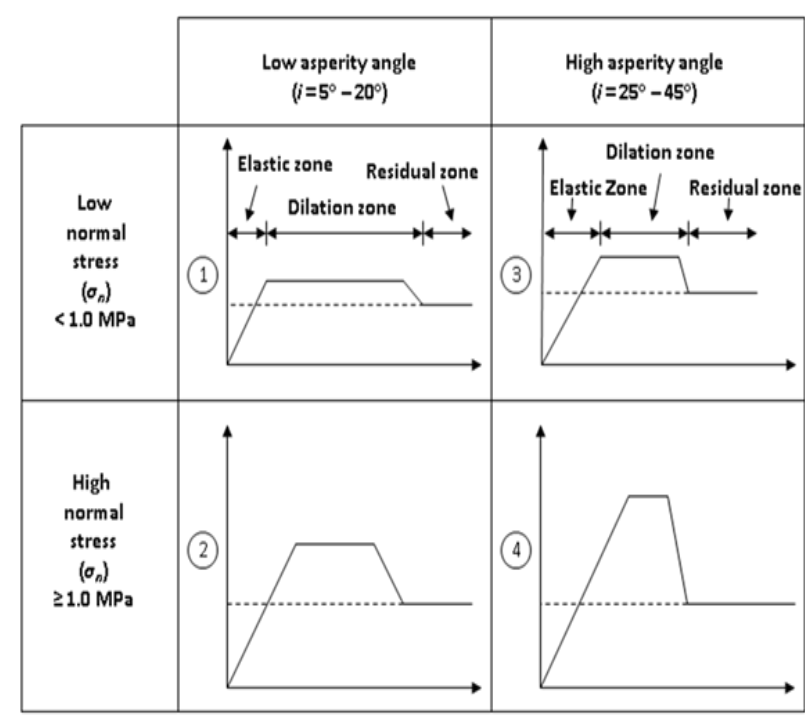

Fig -11: Various conceptual models between shear stress and shear displacement relationships.

\section{CONCLUSIONS}

This paper discusses a study of the variation in shear strength of saw-tooth model joints in different constant normal loading conditions. The following main conclusions may be drawn from this investigation:

a) In CNL testing at lower normal stress levels, it was found that dilation of the asperities is prominent and shear failure of the asperities took place over a greater displacement. The nature of the shear stressdisplacement curves was ductile.

b) At high normal stresses $\left(\sigma_{n} \geq 1.0 \mathrm{MPa}\right)$, it is observed that dilation is suppressed significantly, and shearing through the asperities dominates the response of the saw-tooth joint. With increased normal stress, dilation decreases, possibly due to asperity degradation. Smaller rate of dilation is observed from the dilation response of test specimens, and reveals that severe damage or shearoff has occurred on the asperity.

c) One important characteristic of the shear stress versus shear displacement curves noticed in the present experimental investigations is the stick-slip behaviour. This stick-slip behaviour is probably due to the momentary reduction in shear stress as individual asperities are sheared. The stick-slip behaviour became increasingly pronounced with increasing normal stress.

d) Under CNL, the laboratory observations verified that the asperity degradation is less prominent at low normal stress levels $\left(\sigma_{n}<1.0 \mathrm{MPa}\right)$. A visual observation of joint surfaces indicated that asperities sheared considerably at elevated normal stresses. 
e) At higher normal stresses ( $\sigma_{n} \geq 1.0 \mathrm{MPa}$ ), the nature of shear stress-displacement tends to be more brittle and the asperity failure was noticed to begin with the frontal asperities and followed a progressive failure rather than simultaneous failure of the asperities in contact.

f) It was observed from the test results that the peak shear stress increases with the increase in normal stress. The brittleness of the shear stress-shear displacement response also increases with increasing normal stress.

g) With an increased normal stress and an asperity angle of saw-tooth shaped joints, a progressive degradation of asperities occurred which increases peak shear strength and reduces dilation zone. It may be noted that joints with increasing asperity height causes greater degree of dilation with increased shear resistance for the same levels of normal stress.

h) It is observed that peak shear strength increase with an increasing shear displacement rate from 0.314 to $1.01 \mathrm{~mm} / \mathrm{min}$ under same normal stresses. However, from overall test results, it is found that rate of shear displacement has an insignificant effect on peak shear strength.

i) It was observed from the test results, that in lowangled joints, the peak shear stress reached at a greater displacement and in the high-angled joints the peak shear stress reached at a smaller displacement. This may be attributed to the high stress concentration around the asperities, which cause enhanced surface degradation, thereby shearing at smaller horizontal displacements.

j) Based on the entire experimental investigations, four conceptual models of shear stress-shear displacements have been developed for saw-tooth shaped joint asperities. In order to improve the models, more investigations should be carried out on real rock joint samples.

\section{REFERENCES}

[1]. Hoek, E., and E.T. Brown. (1980). Underground excavations in rock. The Institution of Mining and Metallurgy. London, U.K.

[2]. Goodman, R.E., and G.H. Shi. (1985). Block Theory and Its Application in Rock Engineering. Englewood Cliffs, NJ, Prentice-Hall.

[3]. Bandis, S., Lumsden, A.C. and Barton, N.R. (1981). Experimental studies of scale effects on the shear behaviour of rock joints. Int. J. Rock Mech. Min. Sci. and Geomech. Abstr., Vol. 18, pp. 1-21.

[4]. Patton, F.D. (1966). Multiple modes of shear failure in rocks. Proc. 1st Cong, Int. Soc. Rock Mech., Lisbon, Vol. 1, pp. 509-513.

[5]. Ladanyi, B. and Archambault, G. (1970). Simulation of shear behavior of jointed rock mass. Proc. 11th Symp. on
Rock Mechanics: Theory and Practice, AIME, New York, pp. 105-125.

[6]. Saeb, S. (1990). A variance on Ladanyi and Archambault's shear strength criterion. Rock Joints, Barton, (ed. Stephansson), Balkema (Rotterdam), pp. 701-705.

[7]. Barton, N. and Choubey, V. (1977). The shear strength of rock joints in theory and practice. Rock Mechanics, Vol. 10, pp. 1-54.

[8]. Saeb, S. and Amadei, B. (1992). Modelling rock joints under shear and normal loading. Int. J. Rock Mech. Min. Sci. and Geomech. Abstr., Vol. 29, No. 3, pp. 267-278.

[9]. Plesha, M.E. (1987). Constitutive models for rock discontinuities with dilatancy and surface degradation. Int. J. Numer. Anal. Methods Geomech. Vol. 11, pp. 345-362.

[10]. Bandis, S.C., Lumsden, A.C. \& Barton, N.R. (1983). Fundamentals of rock joint deformation. Int. J. Rock Mech. Min. Sci. and Geomech. Abstr., Vol. 20, No. 6, pp. 249-268.

[11]. Barton, N. (1973). Review of a new shear strength criterion for rock joints. Engineering geology, Vol. 7, pp. 287332.

[12]. Barton, N. (1974). Review of shear strength of filled discontinuities in rock. Publication No. 105. Oslo, Norwegian Geotechnical Institute, p. 38.

[13]. Barton, N. (1976). Rock mechanics review, the shear strength of rock and rock joints. Int. J. Rock Mech. Min. Sci. and Geomech. Abstr., Vol. 13, pp. 255-279.

[14]. Barton, N.R. (1971). A relationship between joint roughness and joint shear strength. Proc. of Int. Symp. on Rock Mech. Rock Fracture, Nancy, France, p. 1-8.

[15]. Crawford, A.M. and Curran, J.H. (1981). The influence of shear velocity on the frictional resistance of rock discontinuities. Int. J. Rock Mech. Min. Sci. and Geomech. Abstr., Vol. 18, pp. 505-515.

[16]. Goodman, R.E. (1970). The deformability of joints. Determination of the insitu modulus of deformation of rocks. American Society for Testing and Materials, No. 477, pp. 174196.

[17]. Goodman, R.E., and Ohnishi, Y. (1973). Undrained shear testing of jointed rock. Rock Mechanics, Vol. 5, pp. 129149.

[18]. Haberfield, C.M. and Johnston, I.W. (1994). A mechanistically based model for rough rock joints. Int. J. Rock. Mech. Min. Sci. and Geomech. Abstr., Vol. 31, No. 4, pp. 279-292.

[19]. Hoek, E. (1983). Strength of jointed rock masses. Geotechnique, Vol. 33, No. 3, pp. 187-223.

[20]. Indraratna, B., Haque, A. and Aziz, N. (1998). Laboratory modelling of shear behavior of soft joints under constant normal stiffness condition. Geotechnical and Geological Engineering, Vol. 16, pp. 17-44.

[21]. Jing, L., Stephansson, O. and Nordlund, E. (1993). Study of rock joints under cyclic loading conditions. Rock Mech. and Rock Eng., Vol. 26, pp. 215-232.

[22]. Kodikara, J.K. and Johnston, I.W. (1994). Shear behaviour of irregular triangular rock concrete joints. Int. J. 
Rock Mech. Min. Sci. and Geomech. Abstr., Vol. 31, No. 4, pp. 313-322.

[23] Siedel, J.P. and Haberfield, C.M. (1995b). Towards an understanding of joint roughness, Rock Mech. Rock Eng., Vol. 28, No. 2, pp. 69-92.

\section{BIOGRAPHIES}

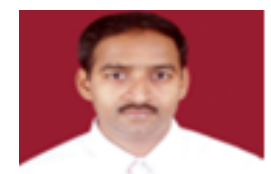

Dr. G. Budi is working as Assistant Professor in the Department of Mining Engineering, Indian School of Mines, Dhanbad. His areas of expertise include rock mechanics and ground control, numerical modelling and tunneling \& underground space technology

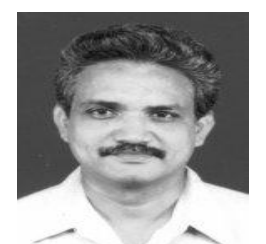

Prof. K.U.M. Rao is working as Professor and Head in the Department of Mining Engineering, IIT Kharagpur. His areas of expertise include rock mechanics, mine development, back filling of mine voids and underground metal mining

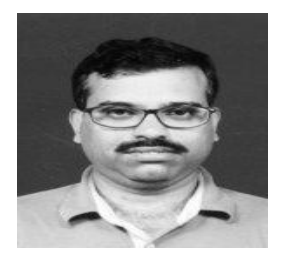

Prof. Debasis Deb is working as Professor in the Department of Mining Engineering, IIT Kharagpur. His areas of expertise include rock mechanics, numerical modelling, ground control and mine design 